\title{
The Frequency of Withdrawal from Acute Care Is Impacted by Severe Acute Renal Failure
}

\author{
RICHARD SWARTZ, M.D., ERICA PERRY, M.S.W., and JAMIE DALEY
}

\begin{abstract}
Introduction: In the general intensive care setting, decisions to withdraw life support when patients deteriorate despite aggressive treatment are estimated to occur in $10 \%$ of all patients and in $40 \%$ of the patients who die. Acute renal failure (ARF) severe enough to necessitate renal replacement therapy $(\mathrm{RRT})$ is associated with in-hospital mortality approximating $50 \%$. Yet the impact of severe ARF on decisions to withdraw treatment has not been previously described. In chronic renal failure patients, voluntary withdrawal from maintenance dialysis occurs in $10 \%-20 \%$ of patients when increasing complications and poor quality of life ensue, and knowing these data facilitates discussions with patients and families. Having similar data for complicated ARF would facilitate decision making for families and caregivers when these difficult situations arise.

Methods: All cases of ARF requiring RRT during 2000-2001 at University of Michigan Hospital $(n=383)$ were entered prospectively into an outcome study at the time RRT was initiated. Comprehensive data collection included demographic and clinical characteristics, outcome and complications, and severity of illness. Additional information for patients who died included cause of death, life-support withdrawal decisions, and the presence of prior advance directives.

Results: Overall mortality in severe ARF (i.e., severe enough to require RRT) was 53\%. Lifesupport withdrawal occurred in $72 \%$ of deaths (compared to $40 \%-50 \%$ reported among general intensive care cases) and was associated with intensive care stay well beyond 2 weeks. Severity of illness, as indicated by modified APACHE III scores, was higher in patients who died than in survivors, but severity of illness was not higher for withdrawal from treatment than death without withdrawal decisions. Life-support withdrawal was not associated with other demographic or clinical characteristics (hospital service, primary admitting diagnosis, ventilator or pressor dependence, sepsis, or initial type of RRT chosen). Prior advance directives were available in $29 \%$ of patients overall, but having advance directives did not predict withdrawal from acute treatment. Death occurred within 2 days of withdrawal in more than $90 \%$ of cases, emphasizing the severity of underlying illness.

Conclusions: Severe ARF reflects the severity of underlying illness, impacts overall survival, and is associated with more frequent withdrawal from aggressive treatment. High severity of illness and prolonged intensive care without improvement beyond 2 weeks presage decisions to withdraw treatment and signal patients and caregivers that death is imminent and that further aggressive care should be reconsidered or limited.
\end{abstract}

Division of Nephrology, Department of Internal Medicine, University of Michigan Health System, Ann Arbor, Michigan. 


\section{INTRODUCTION}

$\mathbf{T}$ He MORTALity OF ACUTE RENAL FAILURE (ARF) severe enough to require renal replacement therapy (RRT) is approximately $50 \%^{1-3}$ and is related largely to underlying comorbidity. ${ }^{4-6}$ RRT can save some lives, and newer RRT modalities such as continuous RRT may have some advantages. ${ }^{6-9}$ But ARF patients with multisystem illness often have difficult courses and succumb despite aggressive medical care and state-of-the-art RRT. There are now a number of scoring systems for predicting mortality generally in complex medical cases ${ }^{10,11}$ and more specifically in the setting of severe ARF. 1,5,12 Yet these scoring systems can only predict outcome on the basis of specific objective clinical data and cannot account for the "human" factor in the decision-making by families and caregivers. ${ }^{13,14}$

The setting of renal failure and RRT treatment is one in which end-of-life discussions have become a more frequent phenomenon. In long-term maintenance dialysis (end stage renal disease [ESRD]), patients and families often realize the limitations of long-term treatment and are told that a generally quiet death usually occurs within 2 weeks of withdrawal. ${ }^{15,16}$ As a result, a voluntary decision to withdraw from dialysis occurs in $10 \%-20 \%$ of ESRD deaths. ${ }^{15,17,18}$ However, the degree to which patients with ARF make these types of decisions is not well established. Decisions to limit or withdraw care have been estimated to occur in approximately $10 \%$ of all cases and in $40 \%-50 \%$ of all deaths in intensive care units both in the United States and in the United Kingdom, ${ }^{19-21}$ but such data are sparse and not generally recognized. Given the substantial contribution of ARF to hospital mortality, we hypothesize that ARF necessitating RRT increases not only the complexity of illness but also the likelihood of withdrawal from treatment.

\section{METHODS}

All patients with severe ARF (i.e., severe enough to require RRT) at University of Michigan Hospital are entered prospectively into comprehensive data collection at the onset of RRT. Patients with ARF who receive RRT are identified from the nursing treatment records of the Acute Dialysis Unit, so that all such are patients are included in this review. Patients with moderate or severe chronic renal failure approaching endstage renal disease (glomerular filtration rate [GFR] below $25 \%$ of normal), any history of prior long-term dialysis or prior kidney transplant are excluded from this analysis.

The database includes demographic and comorbidity information, primary admitting diagnostic category, laboratory results, characteristics of treatment, complications, specific time intervals during hospital stay (admission to first day of RRT, duration of RRT, duration of intensive care unit stay, time from withdrawal decision to death, and total hospital days) and outcomes (death in hospital, discharge with renal recovery of renal function sufficient to obviate the need for dialysis, or discharge on maintenance dialysis with end-stage renal disease or ESRD). The general character of this database has been previously described. ${ }^{6}$

Included with these data are any specific and clear decisions to withdraw aggressive supportive treatment (RRT, ventilator, pressor medications) that are documented in medical record progress notes. These decisions were identified "prospectively" in real-time chart review whenever possible, and included the presence of both specific daily progress notes and a do not resuscitate order. In addition, the generic availability (but not necessarily the content) of advance directives and the general category of illness leading directly to the withdrawal decision and/or death itself (e.g., bleeding, cardiac, neurologic, or infection) were determined retrospectively by chart review but were not part of the original comprehensive data collection.

General mortality risk was based on a modified APACHE III score ${ }^{11}$ that was calculated for the day of first RRT treatment rather than on admission, for patients both in and out of the intensive care units, and with estimation of coma score from the medical record. Statistical calculations include Student's $t$ test and $\chi^{2}$ testing where appropriate.

This study was part of a larger ARF surveillance that was approved by the Institutional Review Board for Human Investigation at University of Michigan Health System.

\section{RESULTS}

During the 25-month period between December 1, 1999, and December 31, 2001, 384 patients 
Table 1. Characteristics of All ARF-RRT Patients with Respect to Outcome

\begin{tabular}{lccc}
\hline & $\begin{array}{c}\text { Died }^{\mathrm{a}} \\
203(53 \%)\end{array}$ & $\begin{array}{c}\text { Recovered } \\
138(36 \%)\end{array}$ & $\begin{array}{c}\text { ESRD } \\
43(11 \%)\end{array}$ \\
\hline Age (years) & $57 \pm 16$ & $56 \pm 17$ & $64 \pm 16^{\mathrm{b}}$ \\
Gender (female) & $41 \%$ & $40 \%$ & $47 \%$ \\
Admission to RRT (days) & $9 \pm 13$ & $7 \pm 8$ & $9 \pm 12$ \\
ICU days & $13 \pm 13$ & $20 \pm 17$ & $15 \pm 13$ \\
Total hospital days & $19 \pm 16^{\mathrm{c}}$ & $35 \pm 27$ & $32 \pm 32$ \\
Modified APACHE III & $97 \pm 26^{\mathrm{c}}$ & $67 \pm 22$ & $69 \pm 20$ \\
Total complications & $5.9 \pm 2.0$ & $5.3 \pm 2.3^{\mathrm{c}}$ & $6.2 \pm 2.3$ \\
\hline
\end{tabular}

aThe 203 patients who "died" comprise the population for the subsequent data tables.

bSignificantly different $(p<0.05)$ using Student's $t$ test.

ARF, acute renal failure; RRT, renal replacement therapy; ESRD, end-stage renal disease (chronic dialysis); ICU, intensive care unit.

were identified who developed ARF and required RRT for some period of time. Table 1 lists the general demographic characteristics and outcomes among these patients. Overall in-hospital mortality was $53 \%(203 / 384$ patients), recovery of renal function by the time of discharge occurred in 36\% (138/384 patients), and maintenance dialysis at discharge was required in $11 \%$ (43/384 patients). Not surprisingly, patients who died had shorter overall hospital stays and more severe underlying illness (modified APACHE III), but older age was not a factor, intensive care stay was only marginally shorter and total number of complications was not higher. Not shown in the table but implied by the data, some deaths occurred outside of the intensive care unit because some patients never were in intensive care or were transferred from intensive care before death.

Table 2 shows more specific characteristics in the group of patients who died $(n=203)$. Fully $72 \%$ of the patients who died $(147 / 203)$ had active decisions to withdraw from acute care made by the family (not usually the patient) and caregivers. Table 2 shows that in comparing these two subgroups of deceased patients, there was no difference in the interval between admission and the start of RRT or the total length of stay. There was marginally longer intensive care stay among those patients withdrawn from treatment despite the slightly shorter total length of stay. Withdrawal from treatment was not associated with more severe underlying mortality risk or comorbidity.

Table 3 shows other specific comorbidity factors, comparing withdrawal to no withdrawal in patients who died. Decisions to withdraw from treatment were not related to the clinical service, medical versus surgical, even though medical patients tended to have higher severity of illness, and withdrawal was not associated with any particular category of primary admitting illness. The specific choice of RRT modality also was not related to withdrawal from treatment, even though patients triaged to continuous renal replacement therapy (CRRT) tended to have more severe illness. Finally, patients withdrawn from treatment were not more frequently ventilator dependent, pressor dependent or septic. Not shown in Table 3 , neither the immediate category of terminal complication (cardiac, bleeding, infection, or neurologic) nor the presence of major surgery or organ transplantation characterized patients who were withdrawn from acute treatment.

Figure 1 shows the time from withdrawal of treatment to death. In more than $90 \%$ of cases, this time period was short, less than 48 hours.

Table 2. Characteristics of Deceased Patients $(n=203)$ WITH Respect to WithdraWAl From Acute Treatment ${ }^{a}$

\begin{tabular}{|c|c|c|}
\hline & No withdrawal & Withdrawal \\
\hline $\mathrm{n}$ & 56 & 147 \\
\hline Age (years) & $57 \pm 17$ & $57 \pm 16$ \\
\hline Gender (female) & $22(39 \%)$ & $60(41 \%)$ \\
\hline Admission to RRT (days) & $10.3 \pm 15.8$ & $8.2 \pm 11.5$ \\
\hline ICU days & $13.4 \pm 16.6$ & $17.1 \pm 10.8$ \\
\hline Total hospital days & $20.7 \pm 20.3$ & $18.1 \pm 14.1$ \\
\hline Modified APACHE III & $96.1 \pm 24.4$ & $97.3 \pm 27.0$ \\
\hline Total complications & $6.0 \pm 2.0$ & $5.9 \pm 2.0$ \\
\hline
\end{tabular}

aNo significant differences between groups for any values in this table.

RRT, renal replacement therapy; ICU, intensive care unit. 
Table 3. Clinical Character of Deceased Patients Relative to WithdraWal from Acute Treatment

\begin{tabular}{lcc}
\hline & No withdrawal & Withdrawal \\
\cline { 2 - 3 } $\mathrm{n}$ & 56 & 147 \\
\hline Medical patients & $34(61 \%)$ & $91(61 \%)$ \\
$\quad$ Mod APACHE III & $99.4 \pm 21.0^{\mathrm{a}}$ & $100.4 \pm 29.1^{\mathrm{a}}$ \\
Surgical patients & $22(39 \%)$ & $56(38 \%)$ \\
$\quad$ Mod APACHE III & $90.8 \pm 24.7^{\mathrm{a}}$ & $92.1 \pm 21.0^{\mathrm{a}}$ \\
Primary Diagnosis & & \\
Cardiac $(n=36)$ & $13(23 \%)$ & $23(16 \%)$ \\
Heme/onc $(n=31)$ & $9(16 \%)$ & $22(15 \%)$ \\
Infect/Pulm/Tr $(n=48)$ & $12(21 \%)$ & $36(24 \%)$ \\
Liver $(n=61)$ & $15(22 \%)$ & $46(31 \%)$ \\
$\quad$ Vascular $(n=27)$ & $7(13 \%)$ & $20(14 \%)$ \\
Initial RRT Modality & & \\
CRRT $(n=130)$ & $37(66 \%)$ & $93(63 \%)$ \\
$\quad$ Mod APACHE III & $101.4 \pm 26.0^{\mathrm{a}}$ & $101.6 \pm 27.9^{\mathrm{a}}$ \\
IHD $(n=73)$ & $19(34 \%)$ & $54(37 \%)$ \\
Mod APACHE III & $86.2 \pm 17.7^{\mathrm{a}}$ & $89.7 \pm 23.6^{\mathrm{a}}$ \\
Other comorbidity & & \\
Ventilator $(n=138)$ & $38(68 \%)$ & $100(68 \%)$ \\
Pressors $(n=127)$ & $33(59 \%)$ & $94(64 \%)$ \\
Sepsis $(n=94)$ & $29(52 \%)$ & $65(44 \%)$ \\
\hline
\end{tabular}

aThe modified APACHE III scores for "medical" patients were significantly higher than those for surgery patients, scores for continuous renal replacement therapy (CRRT) were significantly higher than those for intermittent hemodialysis (IHD), and there were no significant differences between "withdrawal" and "no withdrawal" for these groups; all using the Student's $t$ test.

bPrimary diagnoses prompting hospital admission included cardiac, heme/onc (hematology/oncology), $\mathrm{inf} / \mathrm{pulm} / \mathrm{tr}$ (infection, pulmonary, or trauma), liver or vascular disease. There were no differences between withdrawal and no withdrawal among these diagnoses.

cRenal replacement treatment (RRT) modalities included continuous RRT (CRRT) or intermittent hemodialysis (IHD), and there was no difference between withdrawal and no withdrawal among the RRT modalities. APACHE scores were higher among CRRT cases, using the Student's $t$ test.

dThese characteristics were not mutually exclusive, and there were no differences between withdrawal and no withdrawal for these comorbidities.

Shorter time intervals were associated with higher modified APACHE III scores. Withdrawal from treatment included pressors and RRT in all cases, and ventilator in support in most cases in which such support was in use.

Table 4 shows the availability of prior advance directives in the medical records of patients who died. More than $90 \%$ of all records were reviewed for the presence of advance directives (living will and/or durable power of attorney for medical decisions). Advance directives were documented in the medical records for $29 \%$ of patients withdrawn from acute treatment, $35 \%$ of patients who died but were not actively withdrawn from treatment, and $32 \%$ of patients of survivors. Thus, the presence of advance directives did not seem to predict decisions to withdraw from acute treatment in the population treated at this medical center.

\section{DISCUSSION}

The frequency of withdrawal from life support treatment in intensive care patients is estimated to occur in $10 \%$ of all patients and is the proximate cause of death $40 \%-50 \%$ of the time in critical care units in the United States and the United Kingdom. ${ }^{19-21}$ Unpublished data from the medical intensive care unit in our own institution shows that life-support withdrawal occurred in $11 \%$ of all patients and was the proximate cause of death $41 \%$ of the time between 1996 and 2000 . In the present study, withdrawal from acute treatment occurred in $72 \%$ of patients who died with severe ARF, suggesting that severe ARF requiring RRT impacted substantially the decisions that are made. This review also indicated that death usually occurred within 48 hours of withdrawing treatment and was likely the result of a complex multisystem illness that included severe ARF rather than the result of "uremia" or the need for RRT alone.

Even though "futility" is seldom cited directly in discussions concerning withdrawal of treatment, the rate of withdrawal suggests that the

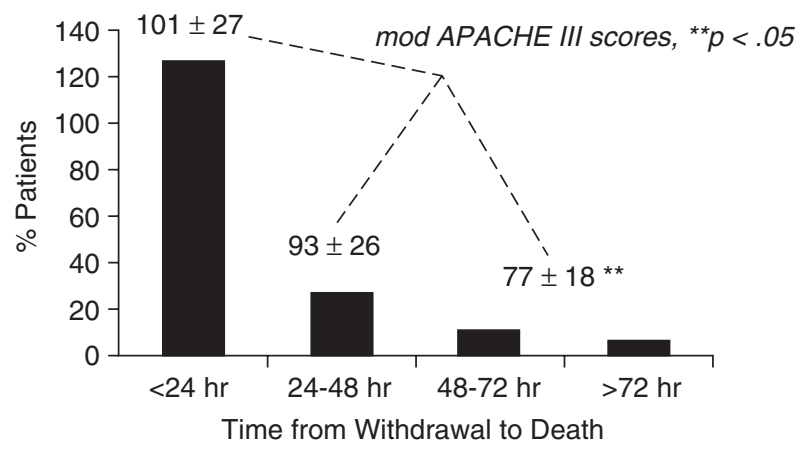

FIG. 1. Distribution of the time from the decision to withdraw treatment to death in all patients for whom such decisions were made $(n=168)$. The average modified APACHE III score (see methods) for each time group is displayed on the graph, with $p<.05$ (Student's $t$ test) comparing the score for patients dying after 48 hours with those dying before 48 hours. 
Table 4. Presence of Prior Advance Directives for Deceased

Patients Relative to Withdrawal from Acute Treatmenta

\begin{tabular}{|c|c|c|c|}
\hline \multirow[b]{3}{*}{$\mathrm{n}$ (record reviewed) } & \multicolumn{3}{|c|}{ Died } \\
\hline & No withdrawal & Withdrawal & Survived \\
\hline & $40 / 56$ & $145 / 147$ & $168 / 181$ \\
\hline \multicolumn{4}{|l|}{ No } \\
\hline Advance Directive & $26(65 \%)$ & $103(71 \%)$ & $114(68 \%)$ \\
\hline Advance Directive & $14(35 \%)$ & $42(29 \%)$ & $54(32 \%)$ \\
\hline
\end{tabular}

${ }^{a}$ A total of 353 of 383 (92\%) of records reviewed for advance directives. No significant differences in frequency of advance directives were demonstrated among the listed groups.

discouraging nature of these complicated cases is evident to all. In some cases, even if families do not verbalize a definite sense of futility, caregivers themselves recognize that death is near at hand. The intuition of caregivers is a reliable predictor of outcome that often closely approximates systematic scoring, ${ }^{22-24}$ but often we do not share our intuition with patients and families, perhaps because we cannot explain why some very ill patients continue to fail and die. ${ }^{14,20}$ As the course of intensive care drags on, families soon sense that death is inevitable, even preferable. That death comes as swiftly as it does when treatment is withdrawn signals the complexity of illness in most of these cases and raises the question of how long discussion about withdrawal should be deferred.

Several other considerations are raised by the present study. First, very high overall severity and the tendency toward a longer portion of the hospital stay in intensive care that we observed suggest that the cases we are treating may simply be more difficult and complex. In fact, we may be undertaking aggressive intervention and continuing life support when we might more wisely defer doing so. Recent data in the general medical community suggest that utilization of high cost care with frequent inpatient-consultative medical services does not necessarily lead to better outcome. ${ }^{25}$ The high mortality and withdrawal rates associated with ARF severe enough to require RRT prompts us to reconsider how we triage our technology and, more important, what we tell patients and families about prognosis and outcomes. $^{26-28}$

Second, it is pivotal that we have ongoing and substantive dialogue with families about how things are going and whether there is progress or not. ${ }^{28-30}$ The construct of a "time-limited trial" of therapy is very useful when intensive care treatment is prolonged. ${ }^{30}$ The data presented here suggest that failure to improve after more than two weeks in the intensive care unit and prospective APACHE III score well over 90, signal the need for discussion of how much longer intensive care should be continued. Our results also demonstrate to families and caregivers that demise occurs quickly when support is withdrawn.

Third, the present study suggests that although prior discussion and advance directives are important in the setting of chronic illness, particularly ESRD, $29,31,32$ the impact of advance directives may be limited in the acute setting, particularly in complicated inpatient illness with severe ARF. Although we did not investigate the nuances of existing advance directives or the specific content of withdrawal decisions in the present study, we observed that withdrawal decisions were made just as often without living will and proxy documents as with such documents. This conclusion does not denigrate the use of such documents but points out that even now, more than 10 years after the Patient Self-determination Act of 1990 mandated consideration of advance directives in federally funded institutions, this important background information only has limited impact in the heat of the moment and may not be specific enough to dictate exactly what the patient might have wanted or what we should do. Perhaps it is wise not to trust our intuition or the available predictive scores at the beginning of treatment. But once the course of illness has become more complicated, particularly in cases with ARF and with clear prospective predictors of high mortality, it may be prudent to pay more attention to any available advance directives that might 
elucidate decisions to withdraw life support treatment.

\section{CONCLUSION}

Fewer than half of the patients who develop severe ARF requiring RRT will survive to discharge. Among those who die, more than $70 \%$ are withdrawn from aggressive treatments that include ventilation, pressors and/or RRT, and most of these patients die within 48 hours of treatment withdrawal. Although advance directives are thought to be important in planning medical care, especially in the chronic care setting, advance directives did not appear to be a prominent factor in decisions to withdraw among patients described in this study. The present review emphasizes that in multiply complex patients with severe renal failure, we must heed our intuitions when these critically ill patients are failing, share what we see and know with families and with patients themselves when possible, and consider applying limits or proposing time-limited trials when treatment extends beyond a reasonable time.

\section{ACKNOWLEDGMENTS}

Support for this study was provided in part by Renal Research Institute, Inc. (New York, NY) and the National Kidney Foundation of Michigan (Ann Arbor, MI).

\section{REFERENCES}

1. DuBose T, Warnock D, Mehta R, Bonventre JV, Hammerman MR, Molitoris BA, Paller MS, Siegel NJ, Scherbenske J, Striker GE: Acute renal failure in the 21st century: Recommendations for management and outcomes analysis. Am J Kidney Dis 1997;29:793-799.

2. Clermont G, Acker C, Angus D, Sirio CA, Pinsky MR, Johnson JP: Renal failure in the ICU: Comparison of the impact of acute renal failure and end-stage renal disease on ICU outcomes. Kidney Int 2002;62:986-996.

3. Tonelli M, Manns B, Feller-Kopman D: Acute renal failure in the intensive care unit: A systematic review of the impact of dialytic modality on mortality and renal recovery. Am J Kidney Dis 2002;40:875-885.

4. Lohr J, McFarlane M, Grantham J: A clinical index to predict survival in acute renal failure patients requiring dialysis. Am J Kidney Dis 1988;11:254-259.
5. Paganini E, Halstenberg W, Goormastic M. Risk modeling in acute renal failure requiring dialysis: The introduction of a new model. Clin Nephrol 1996;46: 206-211.

6. Swartz R, Messana J, Orzol S, Port F: Comparing continuous hemofiltration with hemodialysis in patients with severe acute renal failure. Am J Kidney Dis 1999; 34:424-432.

7. Mehta R: Continuous renal replacement therapies in the acute renal failure setting: Current concepts. Adv Ren Replace Ther 1997;4:81-92.

8. Sandy D, Moreno L, Lee J, Paganini E: A randomized stratified, dose equivalent comparison of CVVHD vs intermittent hemodialysis support in ICU acute renal failure patients [abstract]. J Am Soc Nephrol 1998;9: 225A.

9. Bellomo R, Farmer M, Bhongari S, Porceddu S, Ariens M, M'Pisi D, Ronco C: Changing acute renal failure treatment from intermittent hemodialysis to continuous hemofiltration: Impact on azotemic control. Int J Artif Organs 1999;22:145-150.

10. LeGall R, Loirat P, Alperovitch A, Glaser P, Granthil C, Mathieu D, Mercier P, Thomas R, Villers D: A simplified acute physiology score for ICU patients. Crit Care Med 1984;12:975-977.

11. Knaus W, Wagner D, Draper EA, Zimmerman JE, Bergner M, Bastos PG, Sirio CA, Murphy DJ, Lotring T, Damiano A, et al: The APACHE III prognostic system: risk prediction of hospital mortality for critically ill hospitalized adults. Chest 1991;100:1619-1636.

12. Mehta R, Pascual M, Gruta C, Zhuang S, Chertow GM: Redefining predictive models in critically ill patients with acute renal failure. J Am Soc Nephrol 2002; 13:1350-1357.

13. Al-Saidi F, Diaz-Granados N, Messner H, Herridge M: Relationship between premortem and postmortem diagnosis in critically ill bone marrow transplantation patients. Crit Care Med 2002;30:570-573.

14. Hotchkiss R, Karl I: The pathophysiology and treatment of sepsis. N Engl J Med 2003;348:138-150.

15. Neu S, Kjellstrand C: Stopping long-term dialysis: an empirical study of withdrawal of life-support treatment. N Engl J Med 1986;314:14-20.

16. Cohen L, Germain M, Poppel D, Woods, Pekow P, Kjellstrand C: Dying well after discontinuing the life support treatment of dialysis. Arch Intern Med 2000; 160:2513-2518.

17. Port F, Wolfe R, Hawthorne V, Ferguson CW: Discontinuation of dialysis therapy as a cause of death. Am J Nephrol 1989;9:145-149.

18. United Renal Data System: 1996 Annual Report. Publication 96-3176. Bethesda MD, NIH-NIDDK.

19. Smedira N, Evans B, Grais L, et al. Withholding and withdrawal of life support from the critically ill. $\underline{\mathrm{N}}$ Engl J Med 1990;322:309-315.

20. Ridley S: Uncertainty and scoring systems. Anaesthesia 2003;57:761-767.

21. Prendergast T, Claessens M, Luce J: A national survey of end-of-life care for critically ill patients. Am J Resp Crit Care Med 1998;158:1163-1167. 
22. Kruse J, Thill-Baharozian M, Carlson R: Comparison of clinical assessment with APACHE II for predicting mortality risk in patients admitted to a medical intensive care unit. JAMA 1988;260:1739-1742.

23. McClish D, Powell S: How well can physicians estimate mortality in a medical intensive care unit? $\underline{\text { Med }}$ Decis Making 1989;9:125-132.

24. Brannen A, Godfrey L, Goetter W: Prediction of outcome from critical illness: a comparison of clinical judgment with a prediction rule. Arch Int Med 1989; 149:1083-1086.

25. Wennberg J, Wennberg D: The intensity of care in the last six months of life. In: Dartmouth Atlas of Healthcare in Michigan. The Trustees of Dartmouth College and Blue Cross-Blue Shield of Michigan, 2000. $<$ www.bcbsm.com/atlas/intensity/shtml $>$ (Last accessed July 9, 2004).

26. McCarthy J: Prognosis of patients with acute renal failure in the intensive care unit: A tale of two eras. Mayo Clin Proc 1996;71:117-126.

27. Atkinson S, Bihari D, Smithies M, Daly K, Mason R, McColl I: Identification of futility in intensive care. Lancet 1994;344:1203-1206.

28. Hamel M, Phillips R, Davis R, Desbiens N, Connors AF Jr, Teno JM, Wenger N, Lynn J, Wu AW, Fulkerson W, Tsevat J: Outcomes and cost-effectiveness of initiating dialysis and continuing aggressive care in seriously ill hospitalized adults. Ann Int Med 1997; 127:195-202.
29. Swartz R, Perry E: Advance directives are associated with "good deaths" in chronic dialysis patients. J Am Soc Nephrol 1993;3:1623-1630.

30. Shared decision making in the appropriate initiation of and withdrawal from dialysis. Clinical practice guidelines. Renal Physicians Association and American Society of Nephrology. Washington, D.C.; February 2000.

31. Holley J, Finucane T, Moss A: Dialysis patients' attitudes about cardiopulmonary resuscitation and stopping dialysis. Am J Nephrol 1989;9:245-251.

32. Holley J, Nespor, Rault R: Chronic in-center hemodialysis patients' attitudes, knowledge and behavior toward advance directives. I Am Soc Nephrol 1993;3:1405-1408.

Address reprint requests to: Richard D. Swartz, M.D. Division of Nephrology 3914 Taubman Center Box 0364 University of Michigan Health System Ann Arbor, MI 48109-0363

E-mail: rswartz@med.umich.edu 
This article has been cited by:

1. Helen Noble, Julienne Meyer, Jackie Bridges, Daniel Kelly, Barbara Johnson. 2008. PATIENT EXPERIENCE OF DIALYSIS REFUSAL OR WITHDRAWAL-A REVIEW OF THE LITERATURE. Journal of Renal Care 34:2, 94-100. [CrossRef]

2. Sean M Bagshaw. 2007. The long-term outcome after acute renal failure. Current Opinion in Critical Care 12:6, 561???566. [CrossRef] 